\title{
Drug allergy in children: what should we know?
}

Ji Soo Park, MD, Dong In Suh, MD, PhD

Department of Pediatrics, Seoul National University College of Medicine, Seoul, Korea

The drug allergy "label" may have a lifetime of consequences for a child. Many children with alleged drug allergies are proven to be tolerant to the culprit medication when challenged. The field of drug hypersensitivity is a recently evolving field of research, but studies on its epidemiology and diagnostic tools are lacking in children. Clinical history is significant in the diagnosis and classification of drug hypersensitivity in children. Diagnostic tools have been evaluated in a limited number of children; therefore, the guidelines are mainly in line with those for adults. Here, we review the clinical characteristics, main drugs, risk factors, and diagnosis of drug hypersensitivity to aid in its accurate diagnosis in children.

Key words: Adverse drug reaction, Drug allergy, Drug hypersensitivity, Drug provocation test

\section{Introduction}

Reactions to at least one drug have been reported in 2.9\%$16.8 \%$ of pediatric patients. ${ }^{1-4)}$ However, only a few self-reported drug reactions are confirmed drug hypersensitivities (DHs). $5,6)$ The drug allergy (DA) "label" of children, an alleged DA diagnosis with or without a proper evaluation, can result in use of less alternative therapies, increasing the risk of antibiotic resistance and higher lifetime medical costs. $\left.{ }^{7}\right)$ Therefore, when DA is reported in pediatric patients, physicians must provide appropriate diagnosis and management or refer them to a pediatric allergy specialist. Here, we review the terminology, epidemiology, clinical manifestations, main causative agents, diagnosis, and risk factors of DA in children.

\section{Definition and classifications}

Adverse drug reaction (ADR) is defined by the World Health Organization as "a response to a drug which is noxious, and unintended, which occurs at doses normally used in man for prophylaxis, diagnosis or therapy of disease, or for the modifi- cation of physiological function." ${ }^{\text {8) }}$ As shown in Fig. 1, ADRs are traditionally divided into type $\mathrm{A}$ and type $\mathrm{B}$ reactions. Type A reactions are dose-dependent predictable consequences of the known pharmacological action of the drug that account for $80 \%$ of ADR cases. Type B reactions are less common, dose-independent, unpredictable, and unrelated to the drug's pharmacological action. ${ }^{9)} \mathrm{DHs}$, part of type $\mathrm{B}$ reactions, are adverse effects of drugs that clinically resemble allergic reactions. DAs are DHs for which a definite immunological mechanism has been demonstrated (Fig. 1). When DA is suspected, DH is the preferred term. ${ }^{10)}$ Clinically, DHs are classified as immediate DH, which occur within 1-6 hours after the last drug administration, and nonimmediate $\mathrm{DH}$, which occur at any time from 1 hour after the initial drug administration. ${ }^{11)}$ DAs are classified according to the Gell and Coombs system of hypersensitivity into type I (drug-specific immunoglobulin E antibodies), type II (cytotoxic reactions mediated by drug-specific immunoglobulin G antibodies), type III (immune complex reactions), and type IV reactions (delayed-type hypersensitivity reactions mediated by cellular immunity). ${ }^{12)}$

\section{Epidemiology}

Accurate data on the epidemiology of $\mathrm{ADR}, \mathrm{DH}$, and DA are rare in children, with most epidemiologic data including both type $A$ and $B$ reactions. ${ }^{1,3,13)}$ The prevalence of reported ADR in children is lower than that in adults in the range of 2.9\%-16.8\% according to different reports (Table 1). ${ }^{1,3-5,13,14)}$ However, among the reported ADRs, the proportion of confirmed DA is as low as 4\% after diagnostic evaluation. ${ }^{5,6,15)}$ According to a nationwide Korean questionnaire, the prevalence of DA symptoms in school children was 4.4\%, but the prevalence of diagnosed DA was only $1.1 \%{ }^{4)}$ In a Turkish survey, the incidence of the parent-reported immediate type $\mathrm{DH}$ was $7.87 \%$; however, after diagnostic workup, the true frequency was $0.11 \% .{ }^{6}$ In contrast to DH in adult patients, the process of collecting and reporting DH largely depends on the parents' perception, and it is not evident whether the missing rate is higher in children. The common culprit drugs causing DHs in children are antibiotics,

Corresponding author: Dong In Suh, MD, PhD. Department of Pediatrics, Seoul National University Hospital, Seoul National University College of Medicine, 101 Daehakro, Jongno-gu, Seoul 03080, Korea 


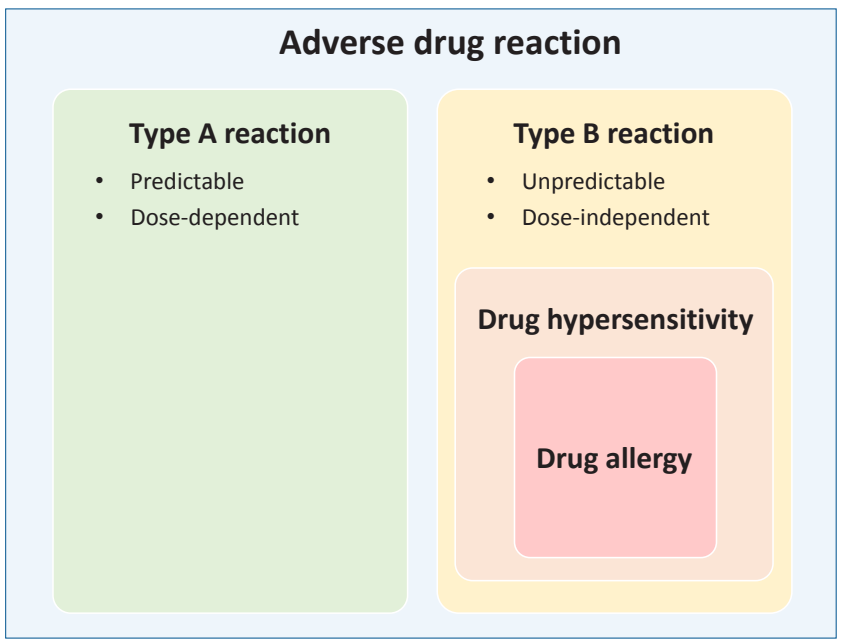

Fig. 1. Adverse drug reaction, drug hypersensitivity, and drug allergy. nonsteroidal anti-inflammatory drugs (NSAIDs), antiepileptic drugs (AEDs), and vaccines. ${ }^{16-18)}$ However, the characteristics of the subject group can largely affect adverse reaction frequency and type.

\section{Clinical manifestations}

In children, cutaneous symptoms, especially maculopapular eruptions (MPEs), are the most frequently reported reactions, followed by gastrointestinal symptoms. ${ }^{5,6,14,17-20)}$ Cutaneous symptoms include urticaria, angioedema, and for some drugs, such as sulfonamides, fixed drug eruptions. ${ }^{16,18,21)}$ Gastrointestinal symptoms included nausea, vomiting, diarrhea, or constipation (Table 2). Isolated respiratory reactions are mostly restricted to NSAIDs but may also present as a part of anaphylaxis. The

Table 1. Studies on the epidemiology of adverse drug reaction, drug hypersensitivity, and drug allergy in children

\begin{tabular}{|c|c|c|c|c|c|}
\hline Study & Research type & Population & $\begin{array}{c}\text { Case } \\
\text { definition }\end{array}$ & Results & Major class of drugs \\
\hline $\begin{array}{l}\text { Impicciatore et } \\
\text { al., 2001 }\end{array}$ & Systematic review & All pediatric & ADR & $\begin{array}{l}\text { Hospitalized: } 9.53 \% \\
\text { Outpatient: } 1.46 \%\end{array}$ & N/A \\
\hline $\begin{array}{l}\text { Smyth et al., } \\
2012^{3)}\end{array}$ & Systematic review & All pediatric & ADR & $\begin{array}{l}\text { Hospitalized: } 0.6 \%-16.8 \% \\
\text { Outpatient: } 0 \%-11.01 \%\end{array}$ & $\begin{array}{l}\text { Antibiotics, antiepileptic drugs, } \\
\text { NSAIDs }\end{array}$ \\
\hline $\begin{array}{l}\text { Lee et al., } \\
2001^{4)^{\prime}}\end{array}$ & $\begin{array}{l}\text { Cross-sectional } \\
\text { survey }\end{array}$ & $\begin{array}{l}\text { General school-age children in } \\
\text { Korea }\end{array}$ & DA & $\begin{array}{l}\text { DH symptoms, ever: } 4.4 \% \\
\text { DA diagnosis, ever: } 1.1 \%\end{array}$ & N/A \\
\hline $\begin{array}{l}\text { Lange et al., } \\
2008^{14)}\end{array}$ & $\begin{array}{l}\text { Cross-sectional } \\
\text { survey }\end{array}$ & $\begin{array}{l}\text { Pediatric patients hospitalized } \\
\text { or visiting ED in Germany }\end{array}$ & DA & $\begin{array}{l}\text { Self-reported DA } 7.5 \% \\
\text { Clinical history suggestive of DH: } 4.2 \%\end{array}$ & $\begin{array}{l}\text { Antibiotics, anti-inflammatory } \\
\text { drugs, Respiratory drugs }\end{array}$ \\
\hline $\begin{array}{l}\text { Cohen et al., } \\
2008^{13)}\end{array}$ & $\begin{array}{l}\text { Public health } \\
\text { surveillance }\end{array}$ & $\begin{array}{l}\text { Pediatric patients visiting ED } \\
\text { in US }\end{array}$ & ADR & $\begin{array}{l}\text { Overall: } 2 / 1000 \text { persons visiting ED } \\
\text { Allergic reactions: } 35 \% \text { of ADR } \\
\text { Vaccine reactions: } 5.9 \% \text { of ADR }\end{array}$ & $\begin{array}{l}\text { Antimicrobials, analgesics, } \\
\text { respiratory medications, } \\
\text { psychotropic medications }\end{array}$ \\
\hline $\begin{array}{r}\text { Rebelo Gomes } \\
\text { et al., 20075) }\end{array}$ & $\begin{array}{l}\text { Cross-sectional } \\
\text { survey } \\
\text { Diagnostic tests }\end{array}$ & $\begin{array}{l}\text { Children visiting outpatient } \\
\text { clinic }\end{array}$ & ADR, DA & $\begin{array}{l}\text { Parent-reported ADR: } 10.2 \% \\
\text { DA suspected by parents: } 6.0 \% \\
\text { Previous DA diagnosis: } 3.9 \% \\
\text { DA positive by testing: } 3 / 34\end{array}$ & $\begin{array}{l}\text { Beta-lactams, NSAIDs, other } \\
\text { antibiotics }\end{array}$ \\
\hline $\begin{array}{l}\text { Erkoçoğlu et al., } \\
2013^{6)}\end{array}$ & $\begin{array}{l}\text { Cross-sectional } \\
\text { survey } \\
\text { Diagnostic tests }\end{array}$ & $\begin{array}{l}\text { General grade 6-8 school } \\
\text { children in Ankara, Turkey }\end{array}$ & $\begin{array}{l}\text { Immediate } \\
\text { type DA }\end{array}$ & $\begin{array}{l}\text { Parent-reported DA: } 7.87 \% \\
\text { Previous DA diagnosis: } 2.73 \% \\
\text { Clinical history suggestive of } \\
\text { immediate type DH: } 1.16 \% \\
\text { DA positive by testing: } 7 / 101\end{array}$ & Antibiotics, NSAIDs \\
\hline
\end{tabular}

ADR, adverse drug reaction; DA, drug allergy; DH, drug hypersensitivity; N/A, not assessed; NSAIDs, nonsteroidal anti-inflammatory drugs.

Table 2. Clinical manifestation and culprit hypersensitivity drugs in children

\begin{tabular}{|c|c|}
\hline Clinical manifestation & Examples of culprit drugs \\
\hline \multicolumn{2}{|l|}{ Dermatologic presentations } \\
\hline Maculopapular exanthema & Beta-lactam antibiotics, glycopeptide, NSAIDs, antiepileptic drugs, vaccines \\
\hline Urticaria, pruritus, erythema & Beta-lactam antibiotics, NSAIDs, acetaminophen, vaccines, NMBAs \\
\hline Angioedema & NSAIDS \\
\hline Fixed drug eruption & Sulfonamides, NSAIDs, carbamazepine \\
\hline \multicolumn{2}{|l|}{ SCARS } \\
\hline AGEP & Beta-lactam antibiotics \\
\hline DRESS & Antiepileptic drugs, beta-lactams \\
\hline SJS/TEN & Beta-lactam antibiotics, antiepileptic drugs, macrolides, acetaminophen, NSAIDs, sulfonamides \\
\hline Anaphylaxis & Beta-lactam antibiotics, NSAIDs, vaccines, NMBAs \\
\hline Serum sickness-like reactions & Cefaclor, sulfonamides \\
\hline
\end{tabular}


frequency of drug-related anaphylaxis is $5 \%-25 \%$ of all anaphylaxis cases according to different reports, ${ }^{22)}$ including a multicenter retrospective review of anaphylaxis in Korea revealing that $10 \%$ of anaphylaxis triggers are drugs. ${ }^{23)}$ The rate of druginduced anaphylaxis is increasing: A United States retrospective analysis showed a $212 \%$ increase in drug-related anaphylaxis (479\%, age $0-4$ years; $140 \%$, age 5-17 years) from 2005 to 2014. ${ }^{24)}$ Other symptoms include headache, lethargy, cough, palpitations, and ocular issues.

Severe cutaneous adverse reactions (SCARs) are a group of rare but potentially life-threatening reactions including acute generalized exanthematous pustulosis, drug reaction with eosinophilia and systemic symptoms (DRESS), Stevens-Johnson syndrome (SJS), and toxic epidermal necrolysis (TEN). ${ }^{25,26)}$ SCARs show widely variable clinical manifestations, such that the pathogenesis is not clear but is thought to involve cytotoxic T-cell activation. However, some findings are consistent across all SCARs: a certain period must pass before SCARs become full-blown, and early drug withdrawal and supportive care with anti-inflammatory medication is the management of choice. ${ }^{26,27)}$

In our previous study based on the Korean SCARs registry, we analyzed 47 pediatric cases of DRESS, SJS, and TEN from 15 tertiary hospitals. ${ }^{27)}$ The latency period between drug exposure and symptoms was longest in DRESS patients (mean, 23.5 days) and shorter in SJS and TEN patients (mean, 4 and 6.5 days, respectively). Cutaneous lesion extent was largest in DRESS cases without mucosal involvement in most cases and without permanent sequelae in all cases. In SJS and TEN patients, the area of skin involvement was smaller but showed slower recovery; a few cases had skin or skin appendage sequelae, while most SJS and TEN patients had mucosal involvement. Finally, 1 of the 4 TEN patients died. The culprit drugs were commonly used, including antibiotics and antipyretics, or uncommon but chronically used drugs, including AEDs, which was comparable to other different pediatric SCAR research. ${ }^{25,27)}$

\section{Major culprit drugs}

The major causes of $\mathrm{DH}$ in children include beta-lactam antibiotics, NSAIDs, and vaccines (Table 2). Studies on the incidence of $\mathrm{DH}$ according to specific drugs is sparse, but it can be estimated from domestic epidemiologic studies on ADRs. ${ }^{28,29)}$

\section{Beta-lactam antibiotics}

Beta-lactam antibiotics, a class of antibiotics that have a betalactam ring in their molecular structures, are classified into 2 major groups (penicillin and cephalosporin) and 4 minor groups (carbapenem, monobactam, oxacephem, and clavulanic acid). Beta-lactam antibiotics are the most prevalent drugs that induce hypersensitivity reactions in children at an estimated 1\%-10\% prevalence rate. ${ }^{2,30-33)}$ According to domestic reports, drug provo- cation tests (DPT) could be safely performed in pediatric patients with higher diagnostic accuracy. ${ }^{34,35)}$ Cross-reactivity between beta-lactam antibiotics is due to the side chain R1 in amoxicillin, ampicillin, and cefaclor, which have identical or almost identical side chains, have been shown to have cross-reactivity by skin testing; and in ceftriaxone and cefotaxime, which have identical side chains and also show skin test cross-reactivity. It is recommended that we evaluate medication side chains to safely challenge betalactams with different side chains. ${ }^{18,36)}$ Finally, a study on the natural history of beta-lactam $\mathrm{DH}$ in children demonstrated results suggestive of tolerance acquisition. ${ }^{37}$

\section{Nonsteroidal anti-inflammatory drugs}

NSAIDs are widely used for pain relief, fever control, and anti-inflammation in children. ${ }^{38-40)}$ The prevalence of $\mathrm{DH}$ to NSAIDs is $0.6 \%-5.7 \%$ in the general population, while the exact prevalence is not reported in children. ${ }^{41,42}$ In an older report, the prevalence of aspirin intolerance in children was $0.3 \%$; recently, in asthmatic children, the prevalence of NSAID hypersensitivity is $0.9 \%{ }^{43)}$ In some studies, the reaction to NSAIDs may exceed that to beta-lactam antibiotics, especially in severe reactions. ${ }^{44-46)}$ In a tertiary hospital in Korea, NSAIDs were the second most common culprit agent in patients who underwent DPT, following beta-lactams. ${ }^{47)}$ As depicted in Fig. 2, the DH to NSAIDs is classified according to the cross-reactivity and symptoms and further by mechanism, timing, and underlying allergic diseases: nonallergic, cross-reactive reactions are classified into NSAIDexacerbated respiratory disease, NSAID-exacerbated cutaneous disease, NSAID-induced urticaria/angioedema or anaphylaxis, and allergic, single-reactor reactions are classified into selective NSAID-induced urticaria/angioedema or anaphylaxis, and selective NSAID-induced delayed reactions. ${ }^{48,49)}$ According to the recent European position paper on childhood NSAIDs, in children under 10 years of age, most responses are nonimmunologic, cross-intolerant, and easily attributed to co-factors such as exercise or infection. ${ }^{50)}$ Thus, they are divided into nonallergic NSAID hypersensitivity and other cases. In children older than 10 years, on the other hand, the reactions are similar to those of adults. According to recent guidelines, DPT is essential ino diagnosing NSAID hypersensitivity in children. ${ }^{16,50)}$ For the management of NSAID hypersensitivity, confirmed diagnosis and classification are required and an alternative NSAID other than the culprit drug is needed. However, because the majority of children under 10 years of age have cross-reactive forms of reactions, DPT of alternative NSAIDs are recommended. ${ }^{50)}$ Although selective NSAIDs for COX2 are not approved for this age group, they have been used safely in practice. ${ }^{51,52)}$

\section{Vaccines}

ADR after vaccination must be differentiated between aller- 


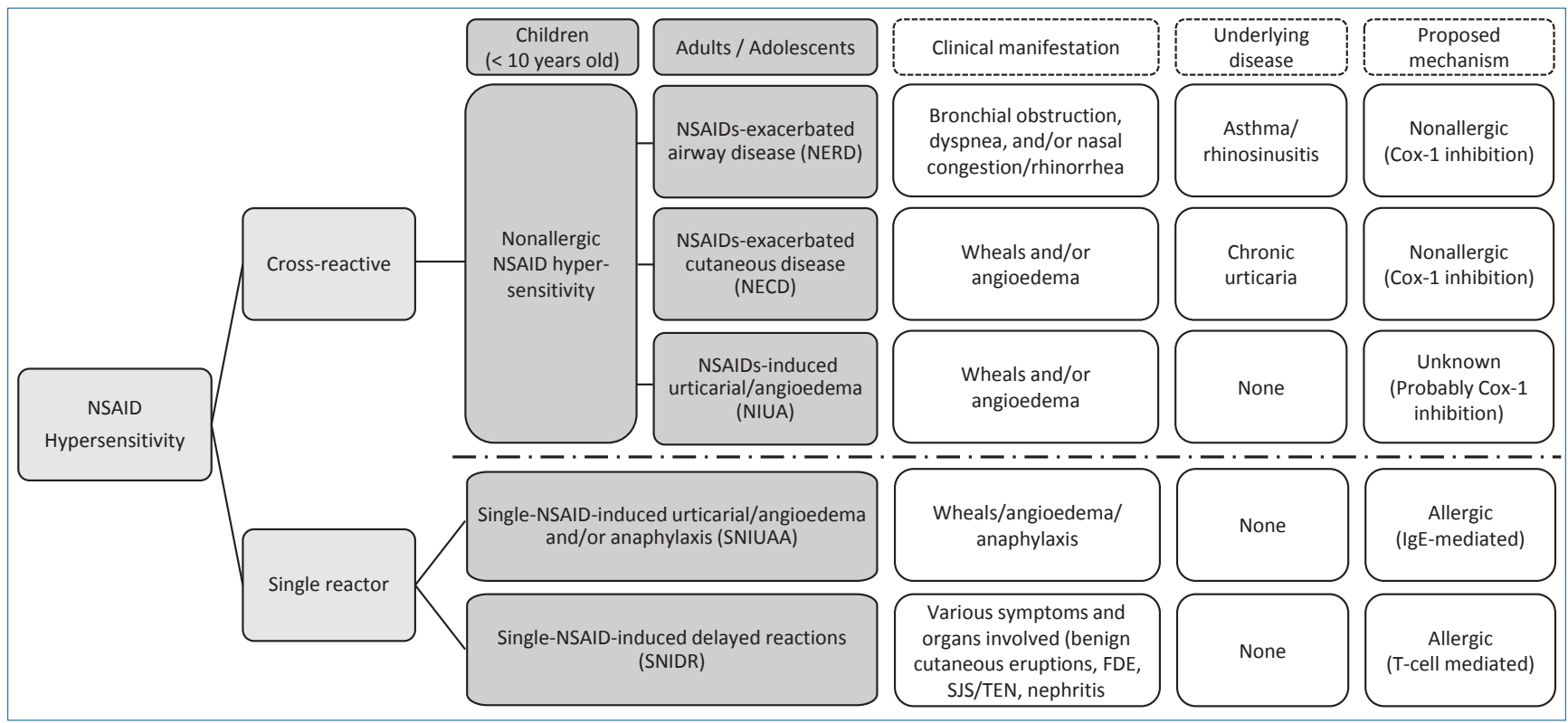

Fig. 2. Classification of nonsteroidal anti-inflammatory drug (NSAID) hypersensitivity. FDE, fixed drug eruption; SJS, Steven-Johnson syndrome; TEN, toxic epidermal necrolysis. Adapted from Kidon et al. Pediatr Allergy Immunol 2018;29:469-80. ${ }^{50)}$

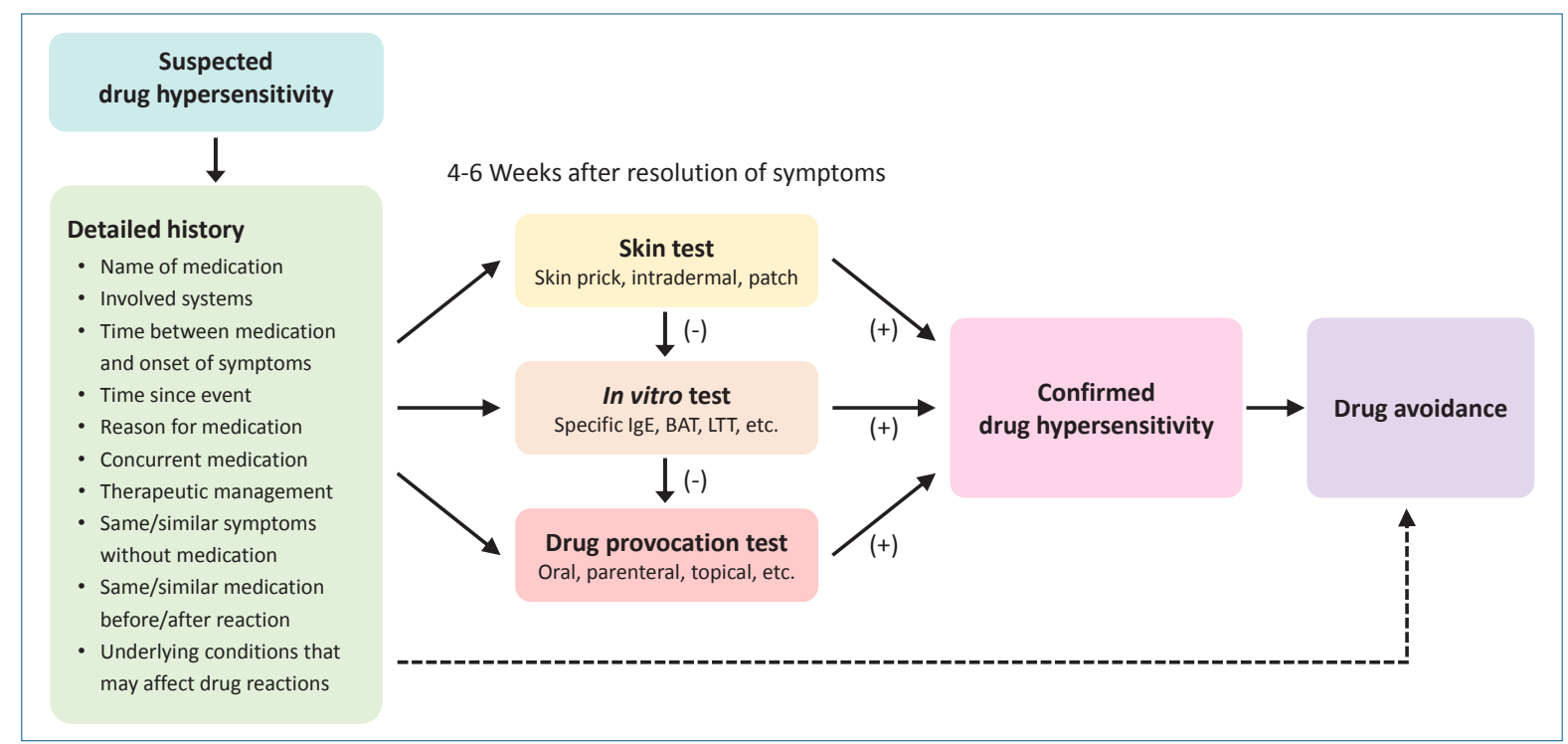

Fig. 3. Generalized schema for the diagnosis of suspected drug hypersensitivity in children. The diagnosis of drug hypersensitivity should be based on detailed history taking and appropriate diagnostic tests, including skin, in vitro, and drug provocation tests. In some cases of severe cutaneous adverse reactions, drug avoidance without additional testing may be recommended. BAT, basophil activation test; LTT, lymphocyte transformation test.

gic and nonallergic reactions. Immediate nonallergic reactions include local injection site reactions (swelling, redness, or soreness) and constitutional symptoms such as fever. These are not contraindications to future vaccine doses. ${ }^{53)}$ Hypersensitivity to vaccine can present as immediate allergic reactions occurring within minutes to 4 hours including urticaria, angioedema, and anaphylaxis, and delayed-type reactions such as rashes occurring hours to days after injection. ${ }^{54)}$ Delayed-type reactions usually do not require allergic evaluation, are self-limiting, and do not contraindicate further doses. ${ }^{55)}$ Immediate hypersensitivity to vaccine in the pediatric population is estimated as 1 per 50,000 to 1 per 1,000,000 doses for most vaccines to 1 per 50,000 doses for diphtheria-tetanus-pertussis vaccines, while vaccine-triggered anaphylaxis is reported to be 1.45 per 100,000 doses. $^{56)}$ Vaccine allergies are rarely triggered by the microbial antigen; rather, they are more commonly induced by other components such as egg protein, stabilizers such as gelatin or milk protein, antibiotics, preservatives, adjuvants, and latex. ${ }^{54)}$ The management of vaccine hypersensitivity starts with verifying immediate allergic reaction through careful history taking and progresses to skin testing with full-strength vaccine and, if available, vaccine components or diluted vaccine in a positive history of anaphylaxis. ${ }^{53)}$ In a patient with history of immediate allergic reaction and a positive skin test result, additional doses of vaccine or other vaccines with com- 
mon ingredients can be administered in graded doses. ${ }^{53)}$ Notably, recent Advisory Committee on Immunization Practices guidelines suggest that persons with egg allergy of any severity may receive influenza vaccine and that only a severe allergic reaction to influenza vaccine is contraindication for future vaccination. ${ }^{57)}$

\section{Diagnosis}

$\mathrm{DH}$ is generally diagnosed, as described in Fig. 3. On the basis of a detailed history taking, appropriate diagnostic testing should be performed as indicated to confirm the causality of the $\mathrm{DH}$.

\section{History taking}

A detailed comprehensive history is essential in the diagnosis of DH. ${ }^{16,58)}$ History taking in pediatric patients often occurs through the caregivers, who may provide exaggerated or biased descriptions. ${ }^{16}$ ) The following items should be evaluated with aid from hospital records at the time of event or pictures if possible: exact name of the medication, time elapsed since event (some allergies wane over time), involved systems (pictures), time between medication use and symptom onset, reason for medication, concurrent medication, diagnostic testing, therapeutic management, same or similar medication before and after reaction, same or similar symptoms without medication, and underlying conditions that may affect or be mistaken for drug reactions. ${ }^{11)}$ Based on the patient's history, if DH is suspected, a specific allergy workup should be performed 4-6 weeks after the resolution of clinical symptoms and signs. ${ }^{10)}$

\section{Skin test}

Skin testing in DH consists of skin prick tests (SPTs), intradermal tests (IDTs), and patch tests. ${ }^{16)}$ Sequential SPT and IDT can safely diagnose suspected IgE-mediated reactions, but the diagnostic value in children is evaluated in a limited number of studies. ${ }^{18,59-62)}$ Penicillin and minor determinants are the only commercial agents for SPT, but even these are not available in Korea, and other skin tests must be prepared according to guidelines. ${ }^{63)}$ Delayed reading of IDT at 48-72 hours and patch testing can be used to evaluate nonimmediate reactions and SCARs. ${ }^{64}$ However, a negative skin test cannot rule out DH and DPT remains the gold standard in diagnosing DH in children. ${ }^{18,60,65)}$ Due to the pain and difficulty of IDT in children, experts are leaning toward DPT before IDT, especially in cases of nonimmediate reactions. ${ }^{16,66)}$

\section{In vitro test}

The only commercially available in vitro tests of $\mathrm{DH}$ are
ImmunoCAP (ThermoFisher, Uppsala, Sweden) assays for a limited number of drugs. Ideally, in vitro tests of specific DHs may be useful in settings of patients taking multiple drugs simultaneously and in those of severe $\mathrm{DH}$ in which skin test is not available or inconclusive and DPT is contraindicated. ${ }^{10)}$ In vitro studies may identify the culprit drug and characterize the active phase of $\mathrm{DH}^{67)}$ To identify the culprit drug of immediate $\mathrm{DH}$, specific IgE measurement and basophil activation test can be used with low sensitivity and high specificity in adults for both assays. ${ }^{67-69)}$ For nonimmediate $\mathrm{DH}$, the lymphocyte transformation test and enzyme-linked immunosorbent spot assays of cytokines and cytotoxic markers (granzyme B, granulysin, interferon- $\gamma$ ) enable the identification of the specific drugassociated, but the sensitivity is yet limited. ${ }^{67,70-72)}$

The measurement of tryptase and histamine release and determination of cellular phenotype in a skin biopsy or the peripheral blood can aid in the characterization of the active reaction phase. ${ }^{67)}$

\section{Drug provocation test}

DPT can be performed to confirm or exclude DH and identify safe alternative treatments in confirmed $\mathrm{DH}$ patients. ${ }^{73)}$ The different routes of DPT (oral, parenteral, topical, and cutaneous) vary depending on the culprit agent. ${ }^{18,58)}$ Several protocols were proposed for children, including single, graded, or multiple-day challenges, but there is no single standardized protocol. ${ }^{73-76)}$ The recent European Academy of Allergy and Clinical Immunology guideline suggests starting with $1 / 10$ of a single age-/weight-appropriate dose and proceeding to a half and then a full dose; for patients with severe reactions, the starting dose may be as low as 1:10000 to $1: 1000{ }^{16)}$ DPT is contraindicated during pregnancy and in cases of acute infection, uncontrolled asthma, or underlying diseases, in which a response to provocation may be noncontrollable with the exception of special circumstances. ${ }^{73)}$ DPT should not be performed for patients who have experienced severe life-threatening reactions such as anaphylaxis or SCARs. 10,73) DPT should be performed under safe conditions with trained staff and emergency resuscitative equipment available. $10,16,73)$

\section{Factors that may affect DH in children}

\section{Age}

In the general population, age extremes are considered risk factors of ADR. ${ }^{77)}$ However, the incidence of ADR or DH by age varies among studies. In an Italian ADR monitoring study in children 0-14 years, the incidence of ADR was the highest in infants $<1$ year with a trend of a higher to lower incidence from younger to older age groups. ${ }^{78)}$ In a study of pediatric admissions due to ADR, the median age of children admitted due to ADR was higher than for those admitted for other reasons. ${ }^{79)}$ In an 
international study that aimed to determine the risk factors associated with ADR in hospitalized children, subjects older than 11 years showed a significantly higher incidence of ADR than those 2-11 years. ${ }^{80)}$ A national surveillance of emergency department visits for $\mathrm{ADR}$ in the US showed a higher incidence of $\mathrm{ADR}$ in children $<1$ and $1-4$ years old, but the majority of ADR in younger children was unintentional overdose and no significant trend among age groups was shown when only allergic reactions were considered. ${ }^{13)}$

\section{Viral infections}

Viral infections, by themselves, present skin rashes that are indistinguishable from $\mathrm{DH}$ and act as a cofactor to DH reactions. Many DPT-negative cases are linked to viral infections. ${ }^{32}$ Several specific viruses are more closely involved in $\mathrm{DH}$ reactions e.g. skin rashes frequently occur when patients with the Epstein-Barr virus are treated with beta-lactam antibiotics. ${ }^{81,82)}$ Certain viruses were recently suspected of being linked with SCARs e.g. human herpes virus infection is closely related to DRESS syndrome. ${ }^{82)}$

\section{Genetic predisposition}

In adults, specific alleles of the human leukocyte antigen (HLA) gene act as risk factors for DHs. HLA B*57:01 and HLA $A * 31: 01$ are related to DRESS or an MPE, while HLA B*15:02 is associated with SJS or TEN. However, it does not show consistent results across all races.

\section{Other points to consider}

For children with chronic complex conditions, the clinical profile and causative medications of spontaneous ADR are different i.e., medicines that are more frequently prescribed for a more extended time result in higher incidence of adverse reactions. ${ }^{21)}$ A high frequency of off-label prescriptions to younger subjects is prone to cause adverse reactions. ${ }^{1,80,83)}$ Polypharmacy is a constant risk factor of ADR. ${ }^{1,16,79,80)}$ Female sex is a risk factor of ADR in adults but not in children. ${ }^{77,79,80)}$ Although biologics are increasingly prescribed these days, there is no specific report to date on the prevalence of risk factors of ADRs to these drugs in children.

\section{Conclusion}

Suspecting the association of medication to an unexpected symptom is the crucial first step of assessment in children. The exact prevalence is not known due to rare and conflicting epidemiological data. We do know that few subjects with DH claims actually undergo a full evaluation to confirm DA. ADR to betalactam antibiotics, NSAIDs, and vaccines present uniquely; therefore, a thorough assessment and careful management are warranted in suspected cases. Hypersensitivity reactions to other medications are rare in pediatric populations, but they can be a significant problem in vulnerable subjects, especially when the alleged drugs are irreplaceable for controlling their underlying diseases. Therefore, a thorough evaluation is essential for recommending drug desensitization or avoidance.

\section{Conflicts of interest}

No potential conflict of interest relevant to this article was reported.

See the commentary "Are you sure that it is a drug allergy?" via https://doi.org/10.3345/cep.2019.01487.

\section{References}

1. Impicciatore P, Choonara I, Clarkson A, Provasi D, Pandolfini C, Bonati $\mathrm{M}$. Incidence of adverse drug reactions in paediatric in/out-patients: a systematic review and meta-analysis of prospective studies. Br J Clin Pharmacol 2001;52:77-83.

2. Vyles D, Chiu A, Simpson P, Nimmer M, Adams J, Brousseau DC. Parent-reported penicillin allergy symptoms in the Pediatric Emergency Department. Acad Pediatr 2017;17:251-5.

3. Smyth RM, Gargon E, Kirkham J, Cresswell L, Golder S, Smyth R, et al. Adverse drug reactions in children--a systematic review. PLoS One 2012;7:e24061.

4. Lee SI, Shin MH, Lee HB, Lee JS, Son BK, Koh YY, et al. Prevalences of symptoms of asthma and other allergic diseases in korean children: a nationwide questionnaire survey. J Korean Med Sci 2001;16:155-64.

5. Rebelo Gomes E, Fonseca J, Araujo L, Demoly P. Drug allergy claims in children: from self-reporting to confirmed diagnosis. Clin Exp Allergy 2008;38:191-8.

6. Erkoçoğlu M, Kaya A, Civelek E, Ozcan C, Cakır B, Akan A, et al. Prevalence of confirmed immediate type drug hypersensitivity reactions among school children. Pediatr Allergy Immunol 2013;24:160-7.

7. Esposito S, Castellazzi L, Tagliabue C, Principi N. Allergy to antibiotics in children: an overestimated problem. Int J Antimicrob Agents 2016;48: 361-6.

8. International drug monitoring: the role of national centres. Report of a WHO meeting. World Health Organ Tech Rep Ser 1972;498:1-25.

9. Edwards IR, Aronson JK. Adverse drug reactions: definitions, diagnosis, and management. Lancet 2000;356:1255-9.

10. Demoly P, Adkinson NF, Brockow K, Castells M, Chiriac AM, Greenberger PA, et al. International Consensus on drug allergy. Allergy 2014; 69:420-37.

11. Khan DA, Solensky R. Drug allergy. J Allergy Clin Immunol 2010;125(2 Suppl 2):S126-37.

12. Pichler WJ. Delayed drug hypersensitivity reactions. Ann Intern Med 2003;139:683-93.

13. Cohen AL, Budnitz DS, Weidenbach KN, Jernigan DB, Schroeder TJ, Shehab N, et al. National surveillance of emergency department visits for outpatient adverse drug events in children and adolescents. J Pediatr 2008;152:416-21.

14. Lange L, Koningsbruggen SV, Rietschel E. Questionnaire-based survey of lifetime-prevalence and character of allergic drug reactions in German children. Pediatr Allergy Immunol 2008;19:634-8.

15. Vezir E, Dibek Misirlioglu E, Civelek E, Capanoglu M, Guvenir H, Ginis T, et al. Direct oral provocation tests in non-immediate mild cutaneous reactions related to beta-lactam antibiotics. Pediatr Allergy Immunol 2016;27:50-4.

16. Gomes ER, Brockow K, Kuyucu S, Saretta F, Mori F, Blanca-Lopez N, et al. Drug hypersensitivity in children: report from the pediatric task force of the EAACI Drug Allergy Interest Group. Allergy 2016;71:149-61.

17. Gamboa PM. The epidemiology of drug allergy-related consultations in 
Spanish Allergology services: Alergológica-2005. J Investig Allergol Clin Immunol 2009;19 Suppl 2:45-50.

18. Rukasin CRF, Norton AE, Broyles AD. Pediatric drug hypersensitivity. Curr Allergy Asthma Rep 2019;19:11.

19. Bergmann M, Caubet JC. Specific aspects of drug hypersensitivity in children. Curr Pharm Des 2016;22:6832-51.

20. Gomes ER, Demoly P. Epidemiology of hypersensitivity drug reactions. Curr Opin Allergy Clin Immunol 2005;5:309-16.

21. Kim B, Kim SZ, Lee J, Jung AH, Jung SH, Hahn HJ, et al. Clinical profiles of adverse drug reactions spontaneously reported at a single Korean hospital dedicated to children with complex chronic conditions. PLoS One 2017;12:e0172425.

22. Atanaskovic-Markovic M, Gomes E, Cernadas JR, du Toit G, Kidon M, Kuyucu S, et al. Diagnosis and management of drug-induced anaphylaxis in children: An EAACI position paper. Pediatr Allergy Immunol 2019; 30:269-76.

23. Lee SY, Ahn K, Kim J, Jang GC, Min TK, Yang HJ, et al. A multicenter retrospective case study of anaphylaxis triggers by age in Korean children. Allergy Asthma Immunol Res 2016;8:535-40.

24. Motosue MS, Bellolio MF, Van Houten HK, Shah ND, Campbell RL. Increasing Emergency Department visits for anaphylaxis, 2005-2014. J Allergy Clin Immunol Pract 2017;5:171-5.

25. Dibek Misirlioglu E, Guvenir H, Bahceci S, Haktanir Abul M, Can D, Usta Guc BE, et al. Severe cutaneous adverse drug reactions in pediatric patients: a multicenter study. J Allergy Clin Immunol Pract 2017;5:75763.

26. Duong TA, Valeyrie-Allanore L, Wolkenstein P, Chosidow O. Severe cutaneous adverse reactions to drugs. Lancet 2017;390:1996-2011.

27. Oh HL, Kang DY, Kang HR, Kim S, Koh YI, Kim SH, et al. Severe cutaneous adverse reactions in Korean pediatric patients: a study from the Korea SCAR Registry. Allergy Asthma Immunol Res 2019;11:241-53.

28. Park GM, Park JH, Jung JW, Han HW, Kim JY, Lee E, et al. Pediatric adverse drug reactions collected by an electronic reporting system in a single tertiary university hospital. Allergy Asthma Respir Dis 2016;4:3549.

29. Kim DW, Choi YC, Lee YS, Nam YH, Jung JA. Analysis of pediatric adverse drug reactions reported to regional pharmacovigilance center of a single university hospital. Allergy Asthma Respir Dis 2018;6:263-9.

30. Romano A, Caubet JC. Antibiotic allergies in children and adults: from clinical symptoms to skin testing diagnosis. J Allergy Clin Immunol Pract 2014;2:3-12.

31. Norton AE, Konvinse K, Phillips EJ, Broyles AD. Antibiotic allergy in pediatrics. Pediatrics 2018;141:e20172497.

32. Trubiano JA, Stone CA, Grayson ML, Urbancic K, Slavin MA, Thursky $\mathrm{KA}$, et al. The $3 \mathrm{Cs}$ of antibiotic allergy-classification, cross-reactivity, and collaboration. J Allergy Clin Immunol Pract 2017;5:1532-42.

33. Ibia EO, Schwartz RH, Wiedermann BL. Antibiotic rashes in children: a survey in a private practice setting. Arch Dermatol 2000;136:849-54.

34. Na HR, Lee JM, Jung JW, Lee SY. Usefulness of drug provocation tests in children with a history of adverse drug reaction. Korean J Pediatr 2011; 54:304-9.

35. Noh SR, Yoon J, Cho HJ, Song S, Park GM, Yu J, et al. Outcomes of drug provocation tests in Korean children with suspected drug hypersensitivity reaction. Allergy Asthma Respir Dis 2018;6:26-33.

36. Zagursky RJ, Pichichero ME. Cross-reactivity in $\beta$-lactam allergy. J Allergy Clin Immunol Pract 2018;6:72-81.

37. Tonson la Tour A, Michelet M, Eigenmann PA, Caubet JC. Natural history of benign nonimmediate allergy to beta-lactams in children: a prospective study in retreated patients after a positive and a negative provocation test. J Allergy Clin Immunol Pract 2018;6:1321-6.

38. Neubert A, Verhamme K, Murray ML, Picelli G, Hsia Y, Sen FE, et al. The prescribing of analgesics and non-steroidal anti-inflammatory drugs in paediatric primary care in the UK, Italy and the Netherlands. Pharmacol Res 2010;62:243-8.

39. Lesko SM, Mitchell AA. The safety of acetaminophen and ibuprofen among children younger than two years old. Pediatrics 1999;104:e39.

40. Eustace N, O'Hare B. Use of nonsteroidal anti-inflammatory drugs in infants. A survey of members of the Association of Paediatric Anaesthetists of Great Britain and Ireland. Paediatr Anaesth 2007;17:464-9.

41. Settipane RA, Constantine HP, Settipane GA. Aspirin intolerance and recurrent urticaria in normal adults and children. Epidemiology and review. Allergy 1980;35:149-54.

42. Doña I, Blanca-López N, Torres MJ, García-Campos J, García-Núñez I, Gómez F, et al. Drug hypersensitivity reactions: response patterns, drug involved, and temporal variations in a large series of patients. J Investig Allergol Clin Immunol 2012;22:363-71.

43. Guvenir H, Dibek Misirlioglu E, Capanoglu M, Buyuktiryaki B, Onay ZR, Ginis T, et al. The frequency of nonsteroidal anti-inflammatory drug hypersensitivity in children with asthma. Int Arch Allergy Immunol 2018; 176:26-32.

44. Liew WK, Chiang WC, Goh AE, Lim HH, Chay OM, Chang S, et al. Paediatric anaphylaxis in a Singaporean children cohort: changing food allergy triggers over time. Asia Pac Allergy 2013;3:29-34.

45. Gabrielli S, Clarke AE, Eisman H, Morris J, Joseph L, La Vieille S, et al. Disparities in rate, triggers, and management in pediatric and adult cases of suspected drug-induced anaphylaxis in Canada. Immun Inflamm Dis 2018;6:3-12.

46. Jares EJ, Baena-Cagnani CE, Sánchez-Borges M, Ensina LF, Arias-Cruz A, Gómez M, et al. Drug-induced anaphylaxis in latin american countries. J Allergy Clin Immunol Pract 2015;3:780-8.

47. Choi J, Lee JY, Kim KH, Choi J, Ahn K, Kim J. Evaluation of drug provocation tests in Korean children: a single center experience. Asian Pac J Allergy Immunol 2016;34:130-6.

48. Stevenson DD, Sanchez-Borges M, Szczeklik A. Classification of allergic and pseudoallergic reactions to drugs that inhibit cyclooxygenase enzymes. Ann Allergy Asthma Immunol 2001;87:177-80.

49. Kowalski ML, Asero R, Bavbek S, Blanca M, Blanca-Lopez N, Bochenek $\mathrm{G}$, et al. Classification and practical approach to the diagnosis and management of hypersensitivity to nonsteroidal anti-inflammatory drugs. Allergy 2013;68:1219-32.

50. Kidon M, Blanca-Lopez N, Gomes E, Terreehorst I, Tanno L, Ponvert C, et al. EAACI/ENDA position paper: diagnosis and management of hypersensitivity reactions to non-steroidal anti-inflammatory drugs (NSAIDs) in children and adolescents. Pediatr Allergy Immunol 2018;29:469-80.

51. Sánchez-Borges M, Capriles-Behrens E, Caballero-Fonseca F. Hypersensitivity to non-steroidal anti-inflammatory drugs in childhood. Pediatr Allergy Immunol 2004;15:376-80.

52. Corzo JL, Zambonino MA, Muñoz C, Mayorga C, Requena G, Urda A, et al. Tolerance to COX-2 inhibitors in children with hypersensitivity to nonsteroidal anti-inflammatory drugs. Br J Dermatol 2014;170:725-9.

53. Kelso JM, Greenhawt MJ, Li JT, Nicklas RA, Bernstein DI, BlessingMoore J, et al. Adverse reactions to vaccines practice parameter 2012 update. J Allergy Clin Immunol 2012;130:25-43.

54. McNeil MM, DeStefano F. Vaccine-associated hypersensitivity. J Allergy Clin Immunol 2018;141:463-72.

55. Caubet JC, Ponvert C. Vaccine allergy. Immunol Allergy Clin North Am 2014;34:597-613.

56. McNeil MM, Weintraub ES, Duffy J, Sukumaran L, Jacobsen SJ, Klein NP, et al. Risk of anaphylaxis after vaccination in children and adults. J Allergy Clin Immunol 2016;137:868-78.

57. Grohskopf LA, Sokolow LZ, Broder KR, Walter EB, Fry AM, Jernigan DB. Prevention and control of seasonal influenza with vaccines: recommendations of the Advisory Committee on Immunization PracticesUnited States, 2018-19 Influenza Season. MMWR Recomm Rep 2018; 67:1-20.

58. Joint Task Force on Practice Parameters; American Academy of Allergy, Asthma and Immunology; American College of Allergy, Asthma and Immunology; Joint Council of Allergy, et al. Drug allergy: an updated practice parameter. Ann Allergy Asthma Immunol 2010;105:259-73.

59. Romano A, Gaeta F, Valluzzi RL, Alonzi C, Viola M, Bousquet PJ. Diag. nosing hypersensitivity reactions to cephalosporins in children. Pediatrics 2008;122:521-7.

60. Caubet JC, Kaiser L, Lemaitre B, Fellay B, Gervaix A, Eigenmann PA. The role of penicillin in benign skin rashes in childhood: a prospective study 
based on drug rechallenge. J Allergy Clin Immunol 2011;127:218-22.

61. Ponvert C, Perrin Y, Bados-Albiero A, Le Bourgeois M, Karila C, Delacourt $\mathrm{C}$, et al. Allergy to betalactam antibiotics in children: results of a 20-year study based on clinical history, skin and challenge tests. Pediatr Allergy Immunol 2011;22:411-8.

62. Atanasković-Marković M, Gaeta F, Gavrović-Jankulović M, Cirković Veličković T, Valluzzi RL, Romano A. Diagnosing multiple drug hypersensitivity in children. Pediatr Allergy Immunol 2012;23:785-91.

63. Brockow K, Garvey LH, Aberer W, Atanaskovic-Markovic M, Barbaud A, Bilo MB, et al. Skin test concentrations for systemically administered drugs -- an ENDA/EAACI Drug Allergy Interest Group position paper. Allergy 2013;68:702-12.

64. Lezmi G, Alrowaishdi F, Bados-Albiero A, Scheinmann P, de Blic J, Ponvert C. Non-immediate-reading skin tests and prolonged challenges in non-immediate hypersensitivity to beta-lactams in children. Pediatr Allergy Immunol 2018;29:84-9.

65. Saretta F, Mori F, Cardinale F, Liotti L, Franceschini F, Crisafulli G, et al. Pediatric drug hypersensitivity: which diagnostic tests? Acta Biomed 2019;90(3-S):94-107.

66. Confino-Cohen R, Rosman Y, Meir-Shafrir K, Stauber T, Lachover-Roth I, Hershko A, et al. Oral challenge without skin testing safely excludes clinically significant delayed-onset penicillin hypersensitivity. J Allergy Clin Immunol Pract 2017;5:669-75.

67. Mayorga C, Celik G, Rouzaire P, Whitaker P, Bonadonna P, RodriguesCernadas J, et al. In vitro tests for drug hypersensitivity reactions: an ENDA/EAACI Drug Allergy Interest Group position paper. Allergy 2016; 71:1103-34.

68. Sanz ML, Gamboa PM, Mayorga C. Basophil activation tests in the evaluation of immediate drug hypersensitivity. Curr Opin Allergy Clin Immunol 2009;9:298-304.

69. De Week AL, Sanz ML, Gamboa PM, Aberer W, Sturm G, Bilo MB, et al. Diagnosis of immediate-type beta-lactam allergy in vitro by flowcytometric basophil activation test and sulfidoleukotriene production: a multicenter study. J Investig Allergol Clin Immunol 2009;19:91-109.

70. Pichler WJ, Tilch J. The lymphocyte transformation test in the diagnosis of drug hypersensitivity. Allergy 2004;59:809-20.

71. Polak ME, Belgi G, McGuire C, Pickard C, Healy E, Friedmann PS, et al. In vitro diagnostic assays are effective during the acute phase of delayedtype drug hypersensitivity reactions. Br J Dermatol 2013;168:539-49.

72. Porebski G, Pecaric-Petkovic T, Groux-Keller M, Bosak M, Kawabata
TT, Pichler WJ. In vitro drug causality assessment in Stevens-Johnson syndrome - alternatives for lymphocyte transformation test. Clin Exp Allergy 2013;43:1027-37.

73. Aberer W, Bircher A, Romano A, Blanca M, Campi P, Fernandez J, et al. Drug provocation testing in the diagnosis of drug hypersensitivity reactions: general considerations. Allergy 2003;58:854-63.

74. Mill C, Primeau MN, Medoff E, Lejtenyi C, O'Keefe A, Netchiporouk E, et al. Assessing the diagnostic properties of a graded oral provocation challenge for the diagnosis of immediate and nonimmediate reactions to amoxicillin in children. JAMA Pediatr 2016;170:e160033.

75. Labrosse R, Paradis L, Lacombe-Barrios J, Samaan K, Graham F, Paradis J, et al. Efficacy and safety of 5-day challenge for the evaluation of nonsevere amoxicillin allergy in children. J Allergy Clin Immunol Pract 2018; 6:1673-80.

76. Zambonino MA, Torres MJ, Muñoz C, Requena G, Mayorga C, Posadas $\mathrm{T}$, et al. Drug provocation tests in the diagnosis of hypersensitivity reactions to non-steroidal anti-inflammatory drugs in children. Pediatr Allergy Immunol 2013;24:151-9.

77. Rieder M. Adverse drug reactions in children: pediatric pharmacy and drug safety. J Pediatr Pharmacol Ther 2019;24:4-9.

78. Menniti-Ippolito G, Raschetti R, Da Cas R, Giaquinto C, Cantarutti L. Active monitoring of adverse drug reactions in children. Italian Paediatric Pharmacosurveillance Multicenter Group. Lancet 2000;355:1613-4.

79. Gallagher RM, Mason JR, Bird KA, Kirkham JJ, Peak M, Williamson PR, et al. Adverse drug reactions causing admission to a paediatric hospital. PLoS One 2012;7:e50127.

80. Rashed AN, Wong IC, Cranswick N, Tomlin S, Rascher W, Neubert A. Risk factors associated with adverse drug reactions in hospitalised children: international multicentre study. Eur J Clin Pharmacol 2012;68: 801-10.

81. Chovel-Sella A, Ben Tov A, Lahav E, Mor O, Rudich H, Paret G, et al. Incidence of rash after amoxicillin treatment in children with infectious mononucleosis. Pediatrics 2013;131:e1424-e1427.

82. Mardivirin L, Valeyrie-Allanore L, Branlant-Redon E, Beneton N, Jidar $\mathrm{K}$, Barbaud A, et al. Amoxicillin-induced flare in patients with DRESS (Drug Reaction with Eosinophilia and Systemic Symptoms): report of seven cases and demonstration of a direct effect of amoxicillin on Human Herpesvirus 6 replication in vitro. Eur J Dermatol 2010;20:68-73.

83. Frattarelli DA, Galinkin JL, Green TP, Johnson TD, Neville KA, Paul IM, et al. Off-label use of drugs in children. Pediatrics 2014;133:563-7. 